\title{
Notch pathway: a bistable inducer of biological noise?
}

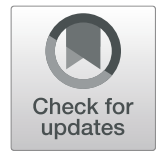

Filip Vujovic ${ }^{1,2}$, Neil Hunter ${ }^{1,2}$ and Ramin M. Farahani ${ }^{1,2^{*}}$ (D)

\begin{abstract}
Notch signalling pathway is central to development of metazoans. The pathway codes a binary fate switch. Upon activation, downstream signals contribute to resolution of fate dichotomies such as proliferation/differentiation or sub-lineage differentiation outcome. There is, however, an interesting paradox in the Notch signalling pathway. Despite remarkable predictability of fate outcomes instructed by the Notch pathway, the associated transcriptome is versatile and plastic. This inconsistency suggests the presence of an interface that compiles input from the plastic transcriptome of the Notch pathway but communicates only a binary output in biological decisions. Herein, we address the interface that determines fate outcomes. We provide an alternative hypothesis for the Notch pathway as a biological master switch that operates by induction of genetic noise and bistability in order to facilitate resolution of dichotomous fate outcomes in development.
\end{abstract}

\section{Introduction}

"I can add colors to the chameleon, change shapes with Proteus for advantages, and set the murderous Machiavel to school." These are the words that Shakespeare used to describe the character of the 'villain' King Richard III. Yet, one would struggle to find better words to illustrate the biology of the elusive protein Notch. In metazoans, imprints of the Notch signalling pathway are evident at every level that a binary decision is made. Notch signalling regulates self-renewal of progenitor cells [1]. Yet, the same pathway activates a differentiation program in progenitor cells [2]. Further, Notch signalling directs the differentiation fate of progenitor cells. In differentiating neural crest populations, cells with increased activity of the Notch signalling pathway (Notch ${ }^{\text {high }}$ ) assume a glial fate bias as opposed to the neuronal differentiation of cells with reduced Notch signalling (Notch ${ }^{\text {low }}$ ) input [3]. Despite redundancies built into the Notch pathway [4], how could simple signalling cues communicate pleiotropic, context dependent, and sometimes opposing outcomes?

Herein, we provide evidence as the basis for an alternative interpretation of the Notch pathway as a master

\footnotetext{
* Correspondence: ramin.mostofizadehfarahani@sydney.edu.au

${ }^{1}$ IDR/Westmead Institute for Medical Research, Sydney, Australia

${ }^{2}$ Faculty of Medicine and Health, University of Sydney, Sydney, NSW 2145, Australia
}

(c) The Author(s). 2019 Open Access This article is distributed under the terms of the Creative Commons Attribution 4.0 International License (http://creativecommons.org/licenses/by/4.0/), which permits unrestricted use, distribution, and

reproduction in any medium, provided you give appropriate credit to the original author(s) and the source, provide a link to the Creative Commons license, and indicate if changes were made. The Creative Commons Public Domain Dedication waiver (http://creativecommons.org/publicdomain/zero/1.0/) applies to the data made available in this article, unless otherwise stated.

\section{Notch signalling pathway: an overview}

Notch signalling pathway is a key evolutionary innovation of metazoans [7]. Notch is a transmembrane protein that includes an extracellular domain consisting of multiple epidermal growth factor-like (EGF) repeats, and an intracellular domain comprising ankyrin (ANK) domains, a transactivation domain and a PEST domain [8]. In canonical Notch signalling, the receptor interacts with its ligand (members of Delta-Serrate-Lag (DSL) type) on a neighbouring cell. In consequence, Notch intracellular domain (NICD) is cleaved [9] and shuttled to the nucleus. NICD can also be generated by non-canonical pathways independent of canonical ligands [10]. In addition, a truncated isoform of Notch that corresponds to NICD is directly transcribed by the activity of an alternative intragenic promoter in T-cells [11]. The topology of Notch signalling pathway is comprehensively reviewed by Andersson et al. [9]. Regardless of the mode of activation, nuclear NICD binds to the CSL family of DNA-binding proteins and activates transcription of targeted genes [12]. 


\section{Notch transcriptome: plastic and versatile}

Genomic loci that are trans-activated downstream to Notch signalling show significant differences in various cell types and different contexts [9]. A consensus transcriptome or even an obligatory responsive gene, is yet to be identified [9]. Even downstream genes such as Hey1 and Hes5 are not consistently trans-activated by Notch signalling [9]. Several factors are involved in the reported versatility of the Notch transcriptome. The Notch transcription complex can bind to two distinct types of genomic response elements, monomer-binding sites and sequence-paired sites [13]. It is estimated that one third of direct Notch target genes are regulated via sequence-paired sites. Cooperative assembly of Notch transcription complexes on sequence-paired sites increases the sensitivity of Notch target genes to variation (i.e. noise) in signal strength [14]. The other important source of variability in Notch signalling is activity of super-enhancers that are in turn regulated by additional tissue-specific transcription factors [15]. Further, the observation that accessibility of Notch-responsive enhancers are regulated by chromatin remodelers [16] may in part explain the reported variability in the Notch signalling cascade. Emergence of noise would also be facilitated by cis-inhibition, where Notch receptors are inhibited by the ligands present within the same cell [17]. However, factors that introduce variability into Notch signalling output are not restricted to the network itself.

Activity of the Notch pathway adapts to various phases of cell cycle with peak signalling detected at M/early G1 phase [18]. Similar to Notch, the downstream targets, e.g. Hes-1, demonstrate sub-oscillations due to negative selfregulation, although at a higher frequency $(\approx 2-3 \mathrm{~h}$ for Hes-1) [19]. Mechanisms that underpin the temporal variability of the Notch signalling pathway expand beyond those operating within an individual cell. This is because Notch signalling propels heterogeneity at a population level by lateral inhibition [20]. In the process of lateral inhibition, a Notch ${ }^{\text {high }}$ cell induces repression of the Notch receptor in the adjacent cells. These observations highlight a major hurdle in generating meaningful population-level readouts of the Notch signalling cascade. A challenge that emanates from the imprinted genetic noise in the functional topology of the Notch pathway. This behavior, however, admits an alternative interpretation. What if the induction of genetic noise is the main function of the Notch signalling cascade? Probing this possibility requires insight into the definition and the utility of noise in biological decision-making.

\section{Noise: a biological perspective}

Although it remains hard to define with precision, genetic noise can be interpreted as random fluctuations in the intensity of a signal, leading to an altered stoichiometric relationship between the input and the output signals. The fluctuations can be instructed by extrinsic and intrinsic sources [5]. Intrinsic noise describes stochastic events that occur within an individual cell and that alter the intensity of a signal. Such stochastic events are an inherent property of transcriptional, posttranscriptional and translational dynamics [21] during generation and transmission of a biological signal. Stochastic events such as replication-transcription conflict [22] and RNA polymerase backtracking mediated by Rloop formation [23] are examples of events that invoke intrinsic noise in an individual cell. On the contrary, extrinsic noise is communicated by exogenous sources such as oscillatory cascades that regulate progression of cell cycle [24] or environmental stressors [25].

Induction or amplification of genetic noise is an important evolutionary pro-survival strategy in unicellular and multicellular organisms. This is because genetic noise fosters phenotypic heterogeneity in a population. In response to extreme environmental stressors, Bacillus subtilis amplifies transcriptional noise to access the program that activates competence [26]. Competence in $B$. subtilis is a transient unstable state during which exogenous DNA is internalised and integrated into the host genome. The unstable state is transiently invoked by stressor-mediated genetic noise and after revision of the genome, competent cells return to the default noncompetent state [27]. Similarly, spatial patterning of the retinal color-vision mosaic during development of Drosophila melanogaster is instructed by stochastic transcriptional fluctuations (transcriptional noise) that bring about probabilistic resolution of dichotomous fate outcomes [28]. The amplification of biological noise during differentiation is required to introduce instability into the steadystate molecular profile of a progenitor cell and to invoke bistability as a conseuqence [6]. In the latter example, key events that instruct noise-dependent specification of differentiation fates in the ommatidium of the Drosophila eye are regulated by the Notch signalling cascade [29]. This finding is not surprising as the Notch signalling pathway interfaces with biological noise at various levels.

\section{Does notch instruct genetic noise at an individual cell level?}

Notch pathway, upon activation, boosts global transcriptional activity by multiple parallel mechanisms. In the absence of NICD, its binding partner, recombination signal binding protein-J (RBP-J), recruits various co-repressors and inhibits gene expression [30]. Binding of NICD to RBPJ and subsequent recruitment of Mastermind Like Transcriptional Coactivator (MAML) to this complex terminates repression and activates transcription [4]. This 
increased gene expression is supported by NICD/RBPJmediated activation of enhancers that improve processivity of RNA polymerase-II (RNAP-II) [15]. Therefore, the primary outcome of Notch signalling is a global amplification of gene expression that is mediated by direct activity of NICD. However, some Notch responsive genes are transcriptional repressors that reshape the transcriptome in a subsequent phase. Here, it is proposed that the clash of primary NICD-mediated transcriptional activation and secondary transcriptional repression facilitates the generation and amplification of biological noise.

As mentioned previously, a major source of genetic noise is altered stoichiometric relationship between transcriptional input and translational output. Such discrepancy is generally induced by enhanced capacity of cells for translation of available transcripts [31]. There is evidence that the Notch signalling cascade plays a major role in regulating the translational capacity of cells by trans-activating the c-Myc gene (Fig. 1) [32, 33]. Myc proto-oncogene is a key pro-anabolic regulator that enhances growth and proliferation rate of cycling cells [34]. In order to support pro-anabolic activity of cycling cells, Myc drives ribosome biogenesis and enhances global protein synthesis during G1 phase of cell cycle [35]. This occurs by RNAPI-mediated transcription of $18 \mathrm{~S}$, $5.8 \mathrm{~S}$ and $28 \mathrm{~S}$ rRNAs [36], and also RNAPII-mediated transcription of ribosomal proteins [37] together with up-regulation of translation initiation factors [38]. It is further proposed the activation of Myc downstream to Notch signalling could improve global translational activity by a second mechanism that involves the mTOR (Target of Rapamycin) pathway. Notch signals provide positive input into the mTOR cascade by upregulating Myc activity [39]. Signals communicated by the mTOR pathway inhibit autophagy [40] and positively regulate ribosome biogenesis and global protein synthesis by enhancing transcription of rRNA genes [41]. Given that $\approx 60 \%$ of the total capacity of the transcriptional machinery is dedicated to ribosome biogenesis in G1 phase of cell cycle $[42,43]$, one would expect a parallel reduction in transcriptional output from other genomic loci in this phase of cycle. Inefficient transcription combined with amplified translational capacity could result in distorted transmission of biological signals and induction of genetic noise [44, 45]. Arguably, the impact of Notch-induced noise will be proportional to the length of G1 phase of cell cycle that accommodates active Myc signalling. The PI3K/ Akt [46] and Wnt/ $\beta$-Catenin [47] are major cascades that accelerate progression through G1 phase and hence restrict translation-related noise. Remarkably, Notch signalling critically interfaces with botch cascades to amplify noise by lengthening $\mathrm{G} 1$ phase.

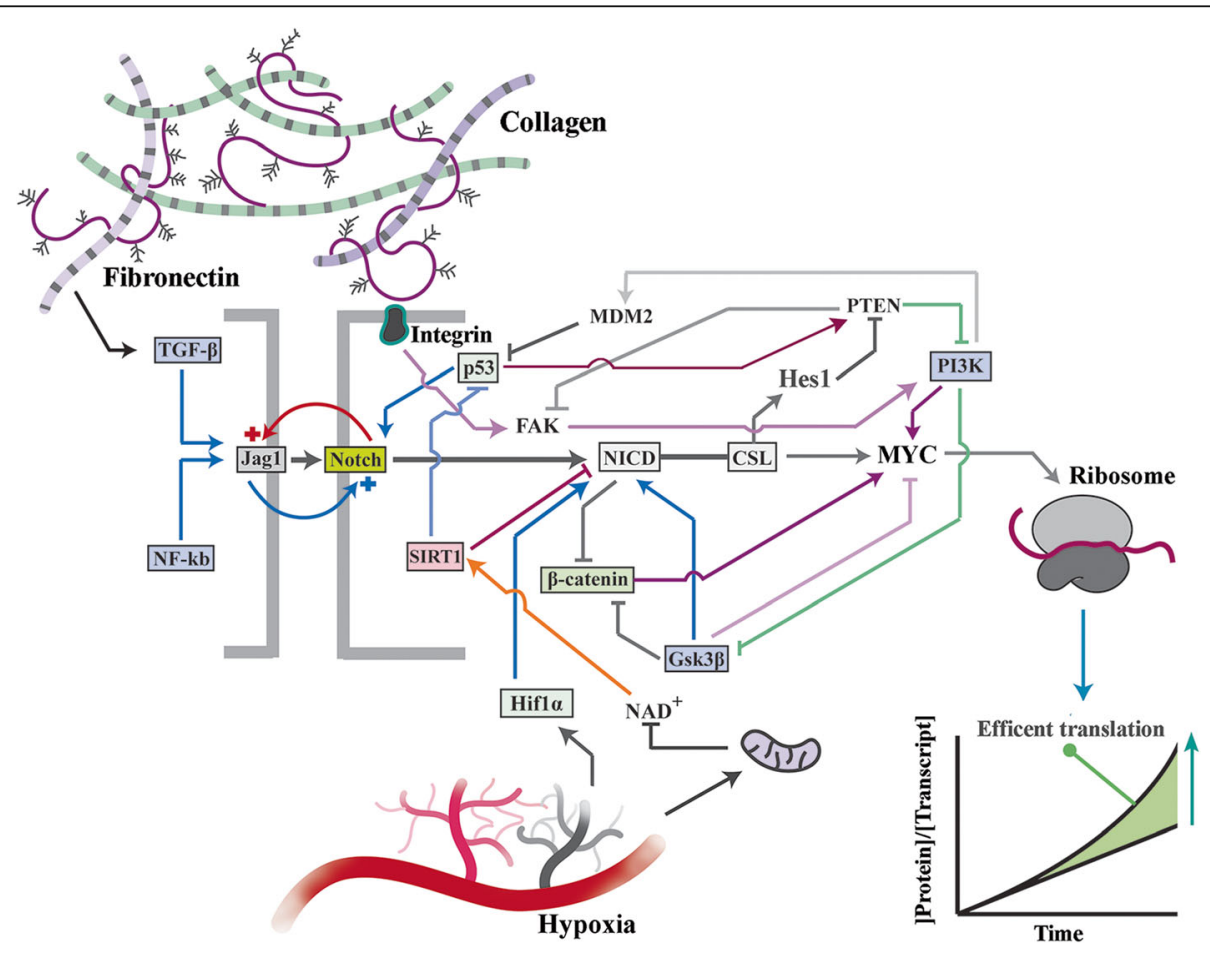

Fig. 1 Notch pathway amplifies intrinsic noise by interactions that improve the efficiency of global protein synthesis. Schematic image shows interaction of a sender $\left(\mathrm{Jag}^{+}\right)$and a receiver $\left(\mathrm{Notch}^{+}\right)$and downstream molecular events instructed by these interactions. System-level interactions of Notch pathway lead to enhanced availability of Myc. Global amplification of protein synthesis following upregulated activity of Myc amplifies noise by distorting the stoichiometric relationship between transcripts and associated proteins 


\section{Altered network topology of the PI3K/Akt pathway in Notch ${ }^{\text {on }}$ cells}

Upon activation of notch signalling, NICD integrates into and alters signalling topology of the PI3K/Akt pathway (Fig. 2a, b). In Notch ${ }^{\text {off }}$ cells, a tripartite negative regulatory loop that comprises PTEN (phosphatase and tensin homologue deleted on chromosome 10), GSK3 $\beta$, and PI3K cascade regulates activity of downstream Akt kinase (Fig. 2b). In Notch ${ }^{\text {off }}$ state, PTEN is phosphorylated by GSK3 $\beta$ on Thr-366 leading to reduced stability of the former protein [48]. Reduced stability of PTEN could stimulate PI3K signalling output as PTEN inhibits the latter pathway by dephosphorylating phosphoinositides [49]. Enhanced PI3K signalling activity, in turn, leads to Akt-mediated phosphorylation and inhibition of GSK3 $\beta$ [50]. This tripartite feedback loop could regulate signalling capacity of Akt subsequent to its activation by mitogens, e.g. growth factors (Fig. 2c). Interestingly, the topology of this loop is radically reconfigured in Notch ${ }^{\text {on }}$ state.

The Notch downstream mediator, Hes-1, represses transcription of PTEN in Notch ${ }^{\text {on }}$ state [51]. In parallel, upregulation of MYC by Notch [32, 33] trans-activates PTEN [52]. This altered topology is consistent with an incoherent type-I feedforward loop (I1-FFL) known to be an effective pulse generator [53]. As such, kinetic modelling using VCell predicted that integration of PTEN into the I1-FFL in the notch ${ }^{\text {on }}$ state would trigger an initial activation (PTEN ${ }^{\text {high }}$ phase) followed by subsequent GSK3 $\beta$-mediated repression (PTEN ${ }^{\text {low }}$ phase) of its phosphatase activity (Fig. 2b). The PTEN pulse in the notch $^{\text {on }}$ state would exert a strong repressive impact on Akt leading to premature termination of the PI3K/Akt signalling activity. Restricted activity of Akt signalling in notch $^{\text {on }}$ state could potentially decelerate progression of cell cycle [46]. This is because Akt-dependent phosphorylation of p21 at Thr-145 is required to abolish the inhibitory impact of p21 on DNA replication [54]. In agreement with our modeling results (Fig. 2c), it was recently demonstrated that PTEN mediates Notch-dependent cell cycle arrest during angiogenesis [55].

\section{Altered activity of the Wnt/ $\beta$-catenin pathway in Notch $^{\text {on }}$ cells}

Downstream to activated Wnt/ signalling, $\beta$-catenin translocates into the nucleus where it binds to the transactivation partner, TCF3/LEF1 [56] and upon which

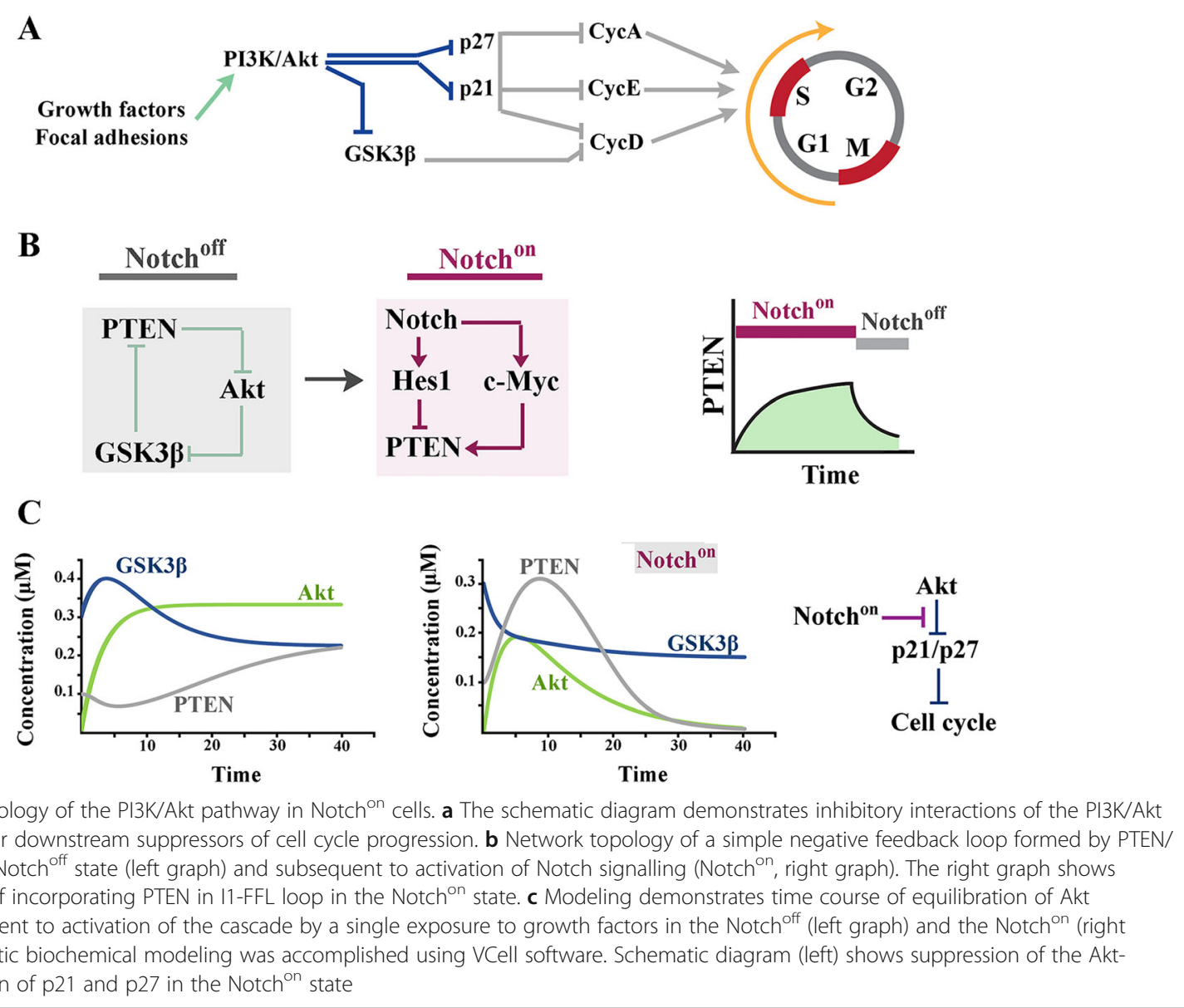


transcription is initiated [57]. Two major drivers of G1 phase of cell cycle, cyclin-D1 [47] and c-Myc [58], are amongst those genomic loci trans-activated by nuclear $\beta$-catenin. It is also known that $\beta$-catenin can suppress p53 acetylation and transcriptional activity [59]. Downregulation of p53 signalling desensitizes G1/S checkpoint $[60,61]$ leading to accelerated transitioning into $S$ phase of cell cycle. It is, therefore, expected that mechanisms that enhance Wnt/ $\beta$-catenin signalling would also support accelerated navigation though short G1 phase [62].

Notch signalling antagonizes the Wnt/ $\beta$-catenin pathway by multiple direct and indirect interactions (Fig. 3a) [63]. It is reported that Notch can physically associate with active $\beta$-catenin and downregulates the latter protein [64]. In addition to direct interaction, downregulation of PI3K/Akt via Notch/PTEN axis [55] (see previous section) could potentially reduce the half-life of $\beta$-catenin. This is because free cytoplasmic $\beta$-catenin is tightly regulated by a destruction complex that recruits the proteins and de-

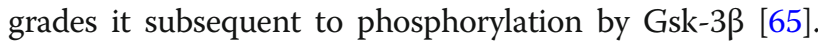
Inhibition of Akt, a negative regulator of GSK3 $\beta$ [50], would potentially boost phosphorylation and degradation of $\beta$-catenin by Gsk-3 $\beta$. Further to inhibition of Gsk3 $\beta$, Akt phosphorylates $\beta$-catenin at Ser-552 and causes its disassociation from junctional complexes followed by shuttling into the nucleus to activate gene expression [66]. Therefore, input from Notch/PTEN axis [55] in the Notch $^{\text {on }}$ state would downregulate the Wnt/ $\beta$-catenin cascade in parallel to inhibition of the PI3K/Akt pathway. Consistent with this proposal, biochemical modeling of $\beta$ catenin/Myc axis predicted accelerated downregulation of both proteins in the Notch ${ }^{\text {on }}$ state (Fig. 3b). Remarkably,
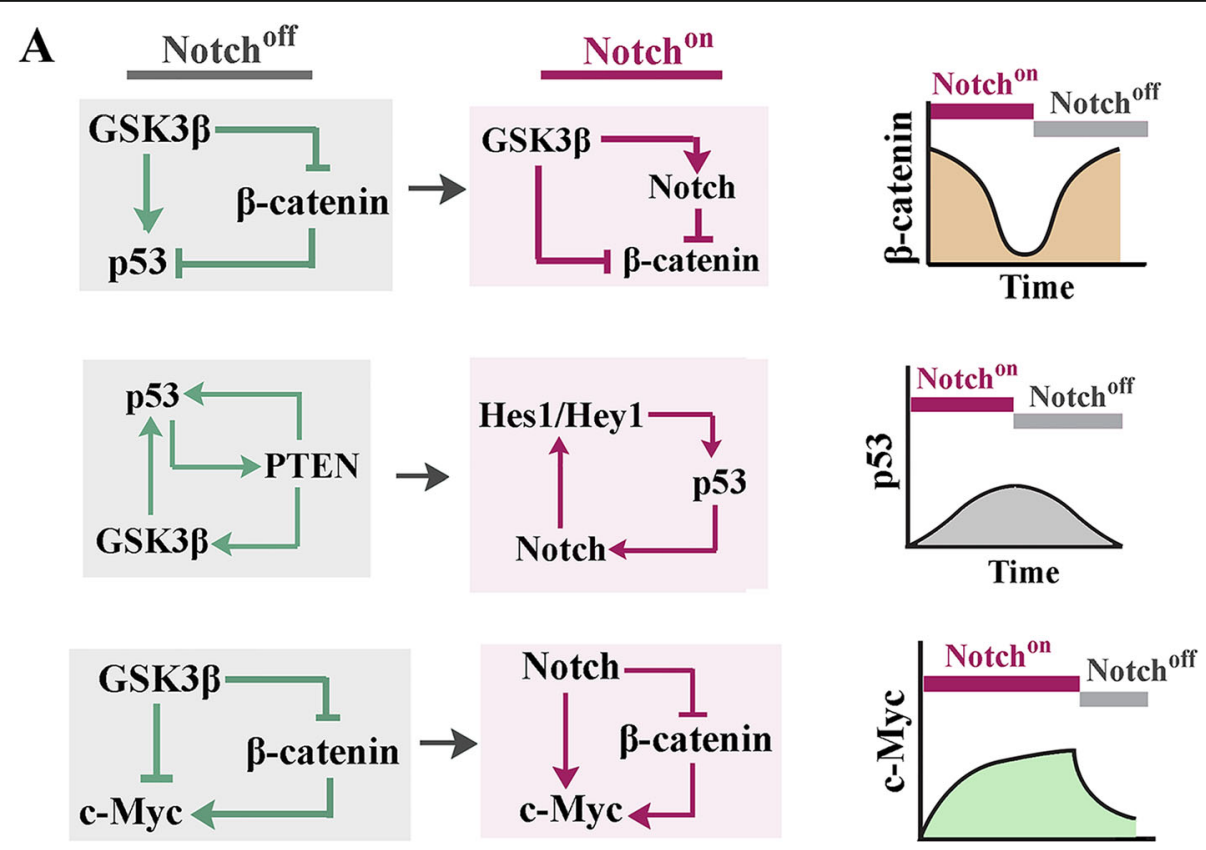

Time

B
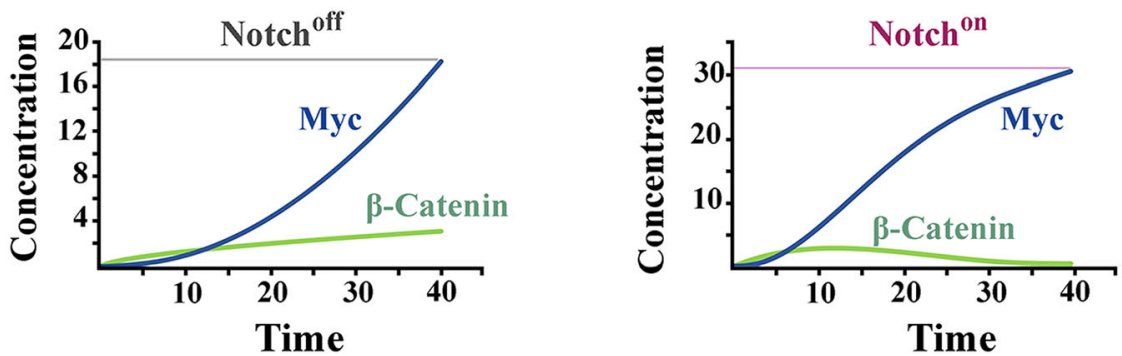

Fig. 3 Altered topology of the Wnt/B-catenin pathway in Notch ${ }^{\text {on }}$ cells. a Left panels show network topology of simple feedback loops that regulate signalling output of the Wnt/ $\beta$-catenin pathway in the Notch off and the Notch ${ }^{\text {on }}$ states. Line diagrams (right) show predicted impact of altered network topology the Notch ${ }^{\text {on }}$ state on cytoplasmic availability of $\beta$-catenin, p53, and Myc. b Modeling demonstrates time course of equilibration of Myc and $\beta$-catenin subsequent to activation in the Notch ${ }^{\text {off }}$ and the Notch ${ }^{\text {on }}$ states. Kinetic biochemical modeling was accomplished using VCell software 
the cross-talk between Notch signalling and cell cycle does not only via modulation of the cascade topology of the PI3K/Akt and the Wnt/ $\beta$-catenin pathways. Notch signalling orchestrates transition from G1 to $S$ phase of cell cycle by multiple other interactions that target the G1/S checkpoint machinery.

\section{Notch signalling input sensitizes G1/S checkpoint}

In the Notch $^{\text {on }}$ state, signalling activity of p53 is enhanced by Hey1-mediated inhibition of the key p53 inhibitor, MDM2 [67]. Stabilization of p53 enhances destruction of CDC6 (Cell Division Cycle 6) by anaphase-promoting complex [68]. CDC6 together with Cdt1 is required for loading of the minichromosome maintenance (MCM) complex in G1 phase of cell cycle and subsequent replication of DNA in S phase [69]. These proteins are components of the pre-replicative complex (pre-RC) that is formed in early G1 in anticipation of DNA replication [70]. Notch signalling also delays entry into $\mathrm{S}$ phase by downregulation of Minichromosome maintenance (MCM) proteins, MCM-2 and MCM-6 [71]. As a consequence, assembly of DNA pre-replication complex and progression of cycling cells into $\mathrm{S}$ phase will be delayed in the Notch ${ }^{\text {on }}$ state. Consistent with this notion, sustained expression of Notch triggers quiescence in cycling cells [2]. To this end, one may question what triggers progression of Notch ${ }^{\text {on }}$ G1-arrested cells into S phase? Self-limiting nature of Notch signalling and de-repression of cell cycle mediated by Notch downstream mediators are potential mechanisms that can propel entry into cell cycle of G1-arrested cells.

Hes1/5 and Hey1/2 are the key downstream mediators of Notch signalling are transcriptional repressors that bind preferentially to the canonical E-box sequence 5 'CACGTG-3' [72]. Hes-1 propels progression of cell cycle by transcriptional repression of the cyclin-dependent kinase inhibitor, p27(Kip1) [73]. In the absence of Hes1, levels of cyclin-dependent kinase inhibitors, p27 and p57, increase significantly leading to impaired progression of cell cycle [74] and precocious differentiation [75]. Similarly, Hey-1 is known to be an effective repressor of p57 [76]. Therefore, the second wave of global transcriptional remodeling mediated by Notch downstream mediators, Hes-1 and Hey-1, facilitates progression of cycling cells into $\mathrm{S}$ phase. Notch signalling, on the other hand, is terminated by an auto-regulatory mechanism. Notch is degraded by autophagy, via uptake into ATG16L1-positive autophagosomes [77]. Enhanced autophagy triggers depletion of NICD and rapid progression through interphase [62]. Sustained Notch signalling requires activation of mTOR (mammalian target of rapamycin) pathway with resultant inhibition of autophagy [78]. This is because signalling by mTOR inhibits ATG1 [79] and hence abolishes initiation of autophagy [80].
In notch ${ }^{\text {on }}$ state, upregulation of PTEN that acts as a negative regulator of mTOR signalling pathway [81] could potentially enhance the autophagic flux (Fig. 4a, b). Akt, on the other hand, activates mTOR by destabilizing TSC1 (Tuberous sclerosis 1) via phosphorylation [82]. Reduced Akt signalling in the notch ${ }^{\text {on }}$ state could contribute to repression of mTOR and amplification of autophagy (Fig. 4a). Induction of autophagy as a consequence of Notch signalling [83] would lead to a self-limiting loop whereby amplified autophagic flux eliminates NICD [62] and facilitates progression into $\mathrm{S}$ phase. This mechanism is reminiscent of the self-regulatory loop that represses the p53 signalling subsequent to induction of autophagy by this protein [84]. Induction of autophagy, however, would have additional consequences for the Notch ${ }^{\text {on }}$ cell.

\section{Notch-induced noise: a destabilizer of cellular memory?}

Cellular memory can be operationally defined as the repertoire of proteins that instruct and stabilize the functional state of a cell. The autophagy-mediated depletion of cytoplasmic protein repertoire is an essential transitional step in cellular reprogramming during development [85]. The most remarkable example of such activity is observed in reprogramming of highly differentiated oocyte into undifferentiated zygote by complete degradation of maternal proteins [86]. Similarly, during somatic cell reprogramming inhibition of mTORC1 and induction of autophagy facilitate transitioning into the early stochastic phase of reprogramming [87]. It is, therefore, proposed that Notch signalling amplifies genetic noise by two parallel mechanisms. Induction of autophagy partially erases the cellular memory by degradation of existing proteins (Fig. 4b). Simultaneously, Notch signalling increases translation efficiency by stimulating progression of cycling cells into $\mathrm{G} 1$ phase $[47,88]$ characterized by efficient ribosome biogenesis (Fig. 4b, c). We propose that increased translational noise in Notch ${ }^{\text {on }}$ state combined with autophagy-mediated destabilisation of cellular memory could induce bistability prior to cellular decision making [6]. The proposed role of Notch signalling in destabilizing cellular memory is bolstered by observation that differentiated quiescent cardiomyocytes reenter cell cycle following activation of Notch pathway [89].

Notch-mediated induction of autophagy and translational noise could also explain the reported versatility of Notch transcriptome [9]. Both autophagy and translational noise enhance temporal stochasticity of the Notch transcriptome by complementary mechanisms. Given the intimate association of autophagy and genetic noise with stressors [90, 91], Notch-induced noise can be regulated by exogenous cues. Such context-dependent (pleiotropic) induction of Notch-mediated noise and bistability is critical for self-organisation [92] during morphogenesis [93] and reprogramming of cells [35] during regeneration. 

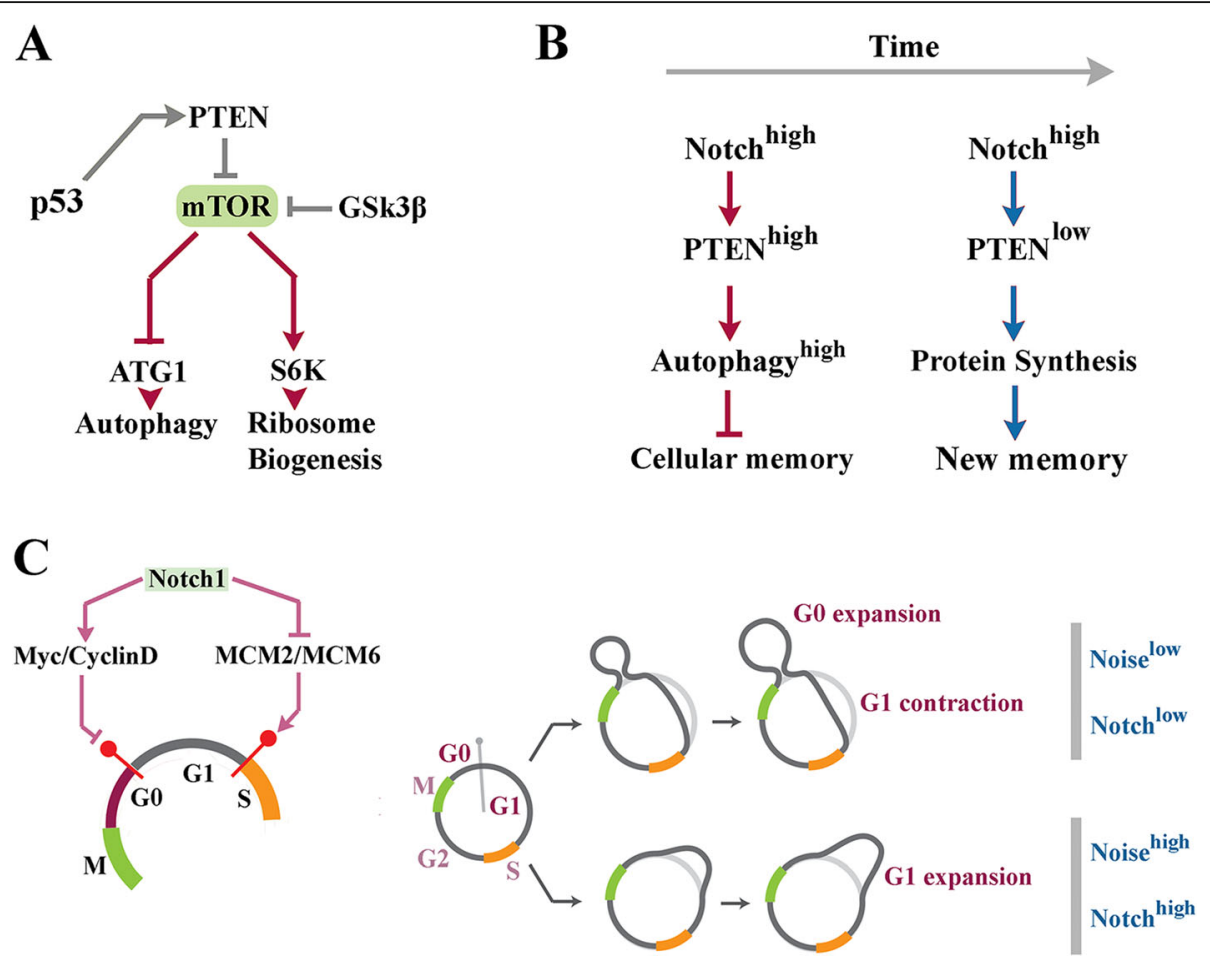

Fig. 4 Notch-induced autophagy and translational noise as destabilizers of cellular memory. a The schematic diagram demonstrates molecular interactions that regulate transitioning between pro-anabolic and pro-catabolic states in a cell. b Subsequent to activation of Notch signalling, the PTEN ${ }^{\text {high }}$ and PTEN ${ }^{\text {low }}$ temporal windows (corresponding to the Notch ${ }^{\text {on }}$ state of Fig. 2c) accommodate pro-catabolic (high autophagy) and pro-anabolic (high protein synthesis) phases. c Notch signals facilitate G0/G1 transition by upregulating Myc and cyclin D1. On the other hand, Notch signals inhibit G1/S transition. In consequence, cycling cells dwell longer in noisy G1 characterized by amplified protein synthesis

\section{Context-dependent induction of noise by Notch signalling}

In mammalian cells, exogenous stressors are gated to Gsk-3ß [94], p53 [95], and NF-kb [96] pathways (Fig. 1a). In this representation, integration of extrinsic stressors such as nutrient deprivation [97] and hypoxia [98] leads to activation of Gsk-3 $\beta$. Phosphorylation by Gsk3 $\beta$ boosts Notch signalling by reducing proteasomal degradation of the latter protein [99]. Likewise, genotoxic stressors, by stabilization of p53 protein [95], would act to stimulate transcription from the notch locus [100]. Another major stressor, oxidative damage, is sensed by the NF-kb signalling pathway. Notch-1 and NF-kb communicate in a positive feedback loop. NF-kb enhances transcription of the Notch ligand Jagged-1 [101], and the downstream targets deltex-1 and hes-5 [102]. It is proposed that Notch, on the other hand, enhances nuclear retention and signalling of NF-kb by a physical interaction with the latter protein [103]. Hence, exogenous stressors that amplify Notch signalling are in turn amplified by Notch pathway. This is analogous to stressor-mediated amplification of genetic noise in B. subtilis albeit with a major difference. In $B$. subtilis, noise is regulated only at an individual cell level. Notch, however, controls population-level dynamics through the canonical signalling pathway.
Notch amplifies genetic noise at a population level Activation of Notch by canonical ligands requires expression of these ligands by adjacent cells (Fig. 5) [4]. Notably, Notch $^{\text {high }}$ cells stimulate expression of the Notch ligand Jagged-1 in adjacent cells via a process of lateral induction $[104,105]$. It then follows that the "noisy state" of Notchhigh cells could be further escalated by positive feedback provided by Jagged- $1^{\text {high }}$ on adjacent cells (Fig. 5). In addition to induction of noise at an individual cell level, Notch integrates signals from other cells in a population to maximise biological noise in Notch ${ }^{\text {high }}$ cells. Arguably, the perpetual amplification of noise in a Notch ${ }^{\text {high }}$ cell could drive the cell towards the tipping point prior to resolution of a binary fate outcome.

\section{Notch and the trio of fate dichotomy, noise and bistability}

Fate dichotomies are a recurring theme of multicellular self-organisation during developmental morphogenesis. Resolution of such dichotomies is the ultimate outcome of a competition between a thermodynamically favoured fate and one that is repressed by the steady-state molecular dynamics of a cell and the cues provided by its surrounding milieu. Proliferation/differentiation dichotomy exemplifies a major developmental bifurcation that 

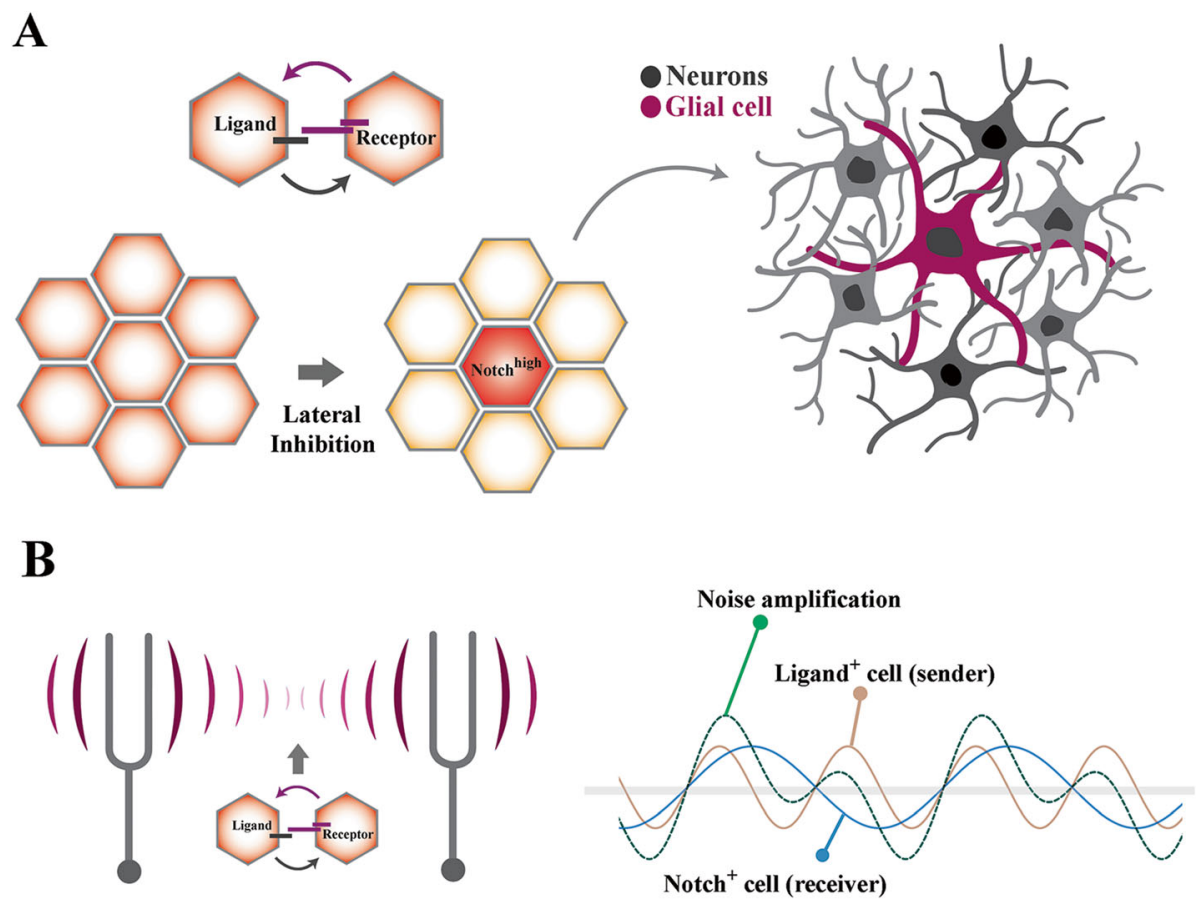

Fig. 5 Integration of intercellular cues amplifies intrinsic noise in the recipient cell. a By lateral inhibition, the interacting cells express Notch ligand and receptors in a mutually exclusive manner. Such polarized expression of the ligands and receptors maximizes induction of noise in the recipient cell. Phenotypically, polarized expression of the ligand and receptors becomes manifest as optimized spatial distribution of differentiation fates associated with Notch high and Notch ${ }^{\text {low }}$ state (e.g. glia versus neuron in development of neurosensory apparatus). $\mathbf{b}$ The intercellular cues provided by neighboring cells amplify noise-inducing activity of notch pathway in a manner akin to harmonic interaction of tuning forks. By this mechanism, every interaction that liberates NICD provides positive feedback into the recipient cell and increases the magnitude and duration of pre-existing noisy state (right schematic image where noise is represented in wave-form)

is iteratively resolved in cycling cells during development. In the presence of growth stimulatory factors (e.g. growth factor), two parallel fates are in direct competition; the thermodynamically favoured fate (i.e. proliferation) is the dominant outcome and quiescence or differentiation are outcomes that are repressed by signalling cues from growth factors. Such repression is a direct consequence of monostability [106] directed by stable topology of biochemical networks that function in a cell (Fig. 6a). We propose that Notch-induced noise causes a transition from monostability to bistability [107] by combined activity of autophagy (that erases cellular memory [85-87]) and translational noise (that prevents reestablishment of steady-state dynamics) (Fig. 6b). In support of our hypothesis, it has been reported that ribosome level and translational efficiency are linked to a binary threshold that controls presence or absence of selected proteins that are involved in directing the differentiation fate of cycling progenitor cells $[108,109]$. In the proposed model, Notchinduced biological noise and the resultant bistability is suggested to tip the balance in favor of thermodynamically less favored outcome (e.g. differentiation in the presence of growth stimulatory factors). This explanation is consistent with the observation that amplified Notch signalling hinders progression through cell cycle while attenuated signalling stimulates proliferation of progenitor cells [2].

\section{Evolutionary remark}

Detailed appraisal of the molecular evolution of the Notch signalling pathway is beyond the scope of the current hypothesis. However, a brief overview of the evolutionary trajectory of Notch protein provides additional insight into its function as a regulator of biological noise. As mentioned previously, Notch protein consists of multiple epidermal growth factor-like repeats, ankyrin domains, and a transactivation domain. The ankyrin domains of Notch are critical for its interactions with other partners and in particular, the CSL family of DNA-binding proteins [110, 111]. From an evolutionary perspective, ankyrin domains are highly conserved structural motifs that are found even in unicellular eukaryotes such as Saccharomyces cerevisiae and Schizosaccharomyces pombe [112]. Swi6 is a key regulatory protein in yeast that contains ankyrin domains [112] and coordinates G1/S transition [113] similar to the role of Notch proteins in regulation of the metazoan cell cycle. As such, it can be argued that the ancestral role of Notch family proteins was regulation 


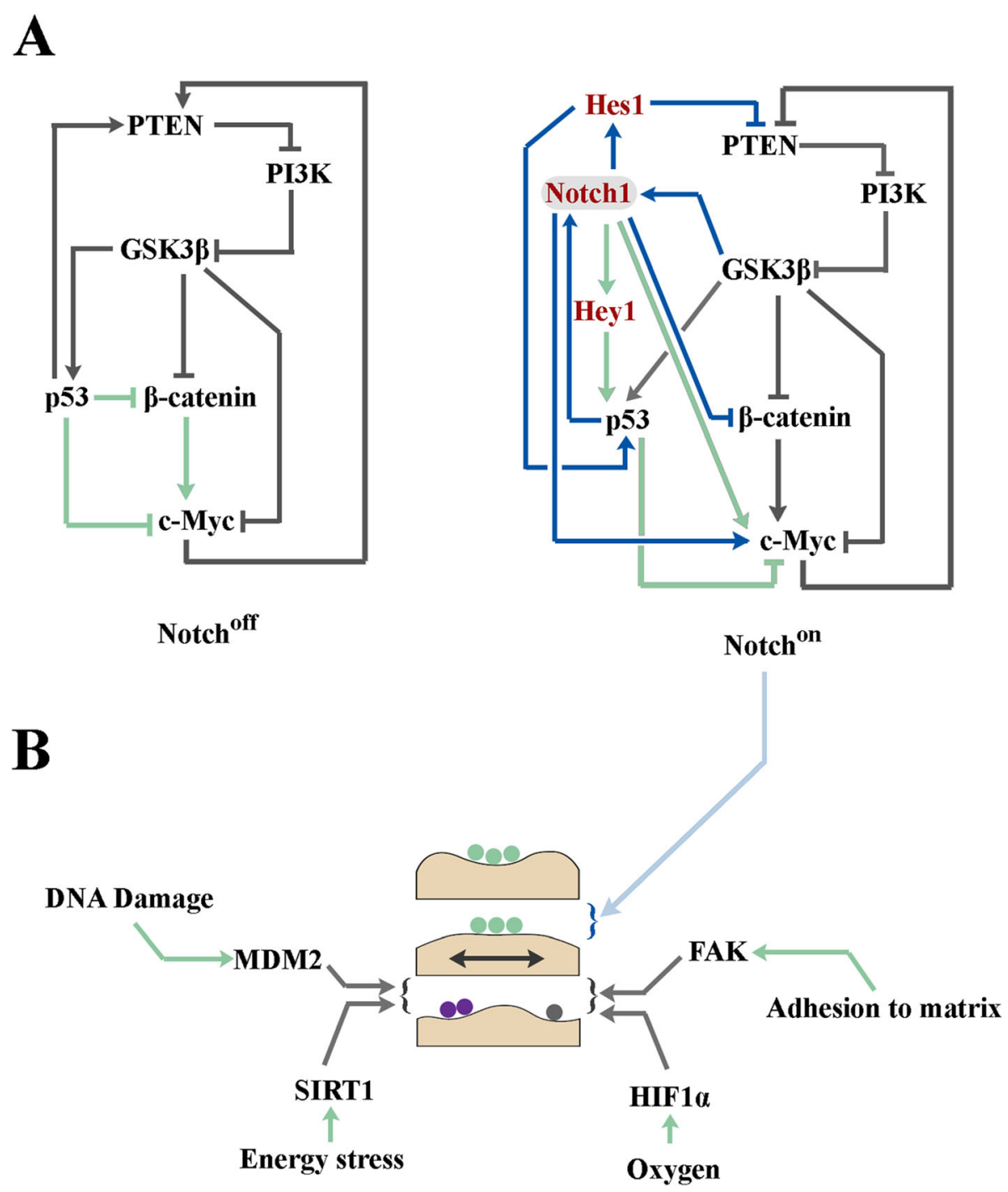

Fig. 6 Noise-induced bistability and resolution of fate dichotomies. a Integrated view of global network topology of Wnt/PI3K/Myc axis following integration of the Notch signaling pathway. $\mathbf{b}$ It is proposed that Notch signaling input combines enhanced autophagic flux with amplifications of translational noise in order to destabilize the existing cellular memory (i.e. destabilize thermodynamic stability) and to invoke bistability prior to biological decision-making. Resolution of such bistability requires integration of exogenous cues that amplify or terminate the Notch signalling pathway

of the cell cycle dynamics. This could have been achieved by integration of environmental cues that provided a dormant capacity for Notch to operate as a "master inducer" of noise, a function that became operational subsequent to evolution of the Notch signalling cascade in metazoan cells [7].

\section{The prospect for experimental validation}

In order to advance the proposed hypothesis, multiple aspects of the Notch signalling pathway need to be carefully dissected. To this end, a major experimental challenge is intimate coupling of Notch signalling and autophagy. As discussed in a previous section, autophagy plays a key role in regulating half-life of NICD [77] and is in turn regulated by Notch signalling [83]. Autophagy, however, receives feedback from various other pathways that supress or stimulate the formation and maturation of autophagosomes [114]. Temporal landscape of autophagic flux is also intimately coupled to cell cycle dynamics [115]. Therefore, experimental conditions need to be standardised with respect to environmental cues and the cycling population should be synchronised with respect to cell cycle. Given the association of autophagy and Notch signalling, conventional methods of cell cycle synchronisation, e.g. serum starvation, that trigger autophagic flux are less useful for this purpose. Alternative methods of cell cycle synchronisation, such as "baby machine" [116], could be more reliable in order to study 
Notch signalling. Apart from experimental difficulties of investigating Notch signalling in an unbiased manner, requirement for an operational definition of genetic noise that is amenable to quantification poses a second challenge. Direct profiling of the activity of PTEN/Akt/ GSK3 $\beta$ axis could provide insight into the level of noise. This method, however, will be confounded by inherent heterogeneity of the multicellular population. On the other hand, cell cycle landscape of a multicellular population, as an indirect but reliable proxy for the level of noise, can be accurately quantified using non-invasive methods described elsewhere [62].

\section{Concluding remarks}

It may be argued that Notch pathway is a master switch that induces and amplifies biological noise in metazoan cells. The proposed role as an inducer of transcriptional noise could oppose the role of $\mathrm{Wnt} / \beta$-catenin in filtering noise $[117,118]$, thereby providing an alternative framework for interpretation of the antagonistic interface of the Notch and the Wnt signalling pathways. In this model, noise-induced bi-stability prior to biological decision-making is suggested to be the direct outcome of the Notch signalling pathway that acts to destabilize the self-organisation signature of the $\mathrm{Wnt} / \beta$-catenin cascade [119] in order to distort imprinted morphological traits and enhance phenotypic plasticity during development of metazoan animals. The framework proposed reconciles versatility of the transcriptome and the predictability of outcomes instructed by Notch signalling.

\section{Abbreviations}

ANK: Ankyrin; DSL: Delta-Serrate-Lag; EGF: Epidermal growth factor; 11FFL: Incoherent type-I feedforward loop; MAML: Mastermind Like Transcriptional Coactivator; MCM: Minichromosome maintenance; mTOR: mechanistic Target of Rapamycin; NICD: Notch Intracellular domain; Pre-RC: Pre-replicative complex; RBP-J: Recombination signal binding proteinJ; RNAP-II: RNA polymerase-II; rRNA: ribosomal RNA

\section{Acknowledgements}

Not applicable.

\section{Authors' contributions}

RMF conception of the work. FV and RMF extensive literature search and manuscript drafting. NH and RMF critical revision of the work. RMF and NH final version approval. All authors read and approved the final manuscript.

\section{Authors' information}

Not applicable.

\section{Funding}

This work was supported by NIDCR (R01 DE015272).

\section{Availability of data and materials \\ Not applicable.}

Ethics approval and consent to participate

Not applicable.

\section{Consent for publication}

All authors read and approved the final manuscript.

\section{Competing interests}

The authors declare that they have no competing interests.

Received: 30 July 2019 Accepted: 4 October 2019

Published online: 22 October 2019

\section{References}

1. Liu J, Sato C, Cerletti M, Wagers A. Notch signaling in the regulation of stem cell self-renewal and differentiation. Curr Top Dev Biol. 2010;92:367-409. https://doi.org/10.1016/S0070-2153(10)92012-7.

2. Ninov N, Borius M, Stainier DY. Different levels of Notch signaling regulate quiescence, renewal and differentiation in pancreatic endocrine progenitors. Development. 2012;139:1557-67. https://doi.org/10.1242/ dev.076000

3. Morrison SJ, et al. Transient Notch activation initiates an irreversible switch from neurogenesis to gliogenesis by neural crest stem cells. Cell. 2000;101: 499-510.

4. Kopan R, llagan MX. The canonical Notch signaling pathway: unfolding the activation mechanism. Cell. 2009;137:216-33. https://doi.org/10.1016/j.cell. 2009.03.045

5. Raser JM, O'Shea EK. Noise in gene expression: origins, consequences, and control. Science. 2005;309:2010-3. https://doi.org/10.1126/science. 1105891.

6. Balazsi G, van Oudenaarden A, Collins JJ. Cellular decision making and biological noise: from microbes to mammals. Cell. 2011;144:910-25. https:// doi.org/10.1016/j.cell.2011.01.030

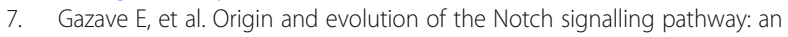
overview from eukaryotic genomes. BMC Evol Biol. 2009;9:249. https://doi. org/10.1186/1471-2148-9-249.

8. Kurooka H, Kuroda K, Honjo T. Roles of the ankyrin repeats and C-terminal region of the mouse notch1 intracellular region. Nucleic Acids Res. 1998;26: 5448-55.

9. Andersson ER, Sandberg R, Lendahl U. Notch signaling: simplicity in design, versatility in function. Development. 2011;138:3593-612. https://doi.org/10. 1242/dev.063610.

10. Heitzler P. Biodiversity and noncanonical Notch signaling. Curr Top Dev Biol. 2010;92:457-81. https://doi.org/10.1016/S0070-2153(10)92014-0.

11. Gomez-del Arco P, et al. Alternative promoter usage at the Notch1 locus supports ligand-independent signaling in T cell development and leukemogenesis. Immunity. 2010;33:685-98. https://doi.org/10.1016/j. immuni.2010.11.008

12. Kovall RA, Blacklow SC. Mechanistic insights into Notch receptor signaling from structural and biochemical studies. Curr Top Dev Biol. 2010;92:31-71. https://doi.org/10.1016/S0070-2153(10)92002-4.

13. Severson E, et al. Genome-wide identification and characterization of Notch transcription complex-binding sequence-paired sites in leukemia cells. Sci Signal. 2017;10. https://doi.org/10.1126/scisignal. aag1598.

14. Nam Y, Sliz P, Pear WS, Aster JC, Blacklow SC. Cooperative assembly of higher-order Notch complexes functions as a switch to induce transcription. Proc Natl Acad Sci U S A. 2007;104:2103-8. https://doi.org/10.1073/pnas. 0611092104.

15. Wang HF, et al. NOTCH1-RBPJ complexes drive target gene expression through dynamic interactions with superenhancers. Proc Natl Acad Sci U S A. 2014;111:705-10. https://doi.org/10.1073/pnas.1315023111.

16. Pillidge Z, Bray SJ. SWI/SNF chromatin remodeling controls Notchresponsive enhancer accessibility. EMBO Rep. 2019;20. https://doi.org/10. 15252/embr.201846944.

17. del Alamo D, Rouault $H$, Schweisguth F. Mechanism and significance of cisinhibition in notch signalling. Curr Biol. 2011;21:R40-7. https://doi.org/10. 1016/j.cub.2010.10.034

18. Del Bene F, Wehman AM, Link BA, Baier H. Regulation of neurogenesis by interkinetic nuclear migration through an apical-basal notch gradient. Cell. 2008;134:1055-65. https://doi.org/10.1016/j.cell.2008.07.017.

19. Hirata $\mathrm{H}$, et al. Oscillatory expression of the bHLH factor Hes 1 regulated by a negative feedback loop. Science. 2002;298:840-3. https://doi.org/10.1126/ science.1074560.

20. Petrovic J, et al. Ligand-dependent notch signaling strength orchestrates lateral induction and lateral inhibition in the developing inner ear. Development. 2014;141:2313-24. https://doi.org/10.1242/dev.108100. 
21. Julicher F, Bruinsma R. Motion of RNA polymerase along DNA: a stochastic model. Biophys J. 1998;74:1169-85. https://doi.org/10.1016/S00063495(98)77833-6

22. Garcia-Muse T, Aguilera A. Transcription-replication conflicts: how they occur and how they are resolved. Nat Rev Mol Cell Biol. 2016;17:553-63. https://doi.org/10.1038/nrm.2016.88.

23. Skourti-Stathaki K, Proudfoot NJ. A double-edged sword: R loops as threats to genome integrity and powerful regulators of gene expression. Genes Dev. 2014;28:1384-96. https://doi.org/10.1101/gad.242990.114

24. Klevecz RR, Bolen J, Forrest G, Murray DB. A genomewide oscillation in transcription gates DNA replication and cell cycle. Proc Natl Acad Sci U S A. 2004;101:1200-5. https://doi.org/10.1073/pnas.0306490101.

25. Mitosch K, Rieckh G, Bollenbach T. Noisy response to antibiotic stress predicts subsequent single-cell survival in an acidic environment. Cell Syst. 2017:4:393-403 e395. https://doi.org/10.1016/j.cels.2017.03.001.

26. Spizizen J. Transformation of biochemically deficient strains of Bacillus subtilis by deoxyribonucleate. Proc Natl Acad Sci U S A. 1958;44: 1072-8.

27. Suel GM, Garcia-Ojalvo J, Liberman LM, Elowitz MB. An excitable gene regulatory circuit induces transient cellular differentiation. Nature. 2006;440: 545-50. https://doi.org/10.1038/nature04588.

28. Mikeladze-Dvali T, et al. The growth regulators warts/lats and melted interact in a bistable loop to specify opposite fates in Drosophila R8 photoreceptors. Cell. 2005;122:775-87. https://doi.org/10.1016/j.cell.2005.07.026.

29. Cooper MT, Bray SJ. R7 photoreceptor specification requires Notch activity. Curr Biol. 2000;10:1507-10.

30. Borggrefe T, Oswald F. The Notch signaling pathway: transcriptional regulation at Notch target genes. Cell Mol Life Sci. 2009;66:1631-46. https:// doi.org/10.1007/s00018-009-8668-7.

31. Ozbudak EM, Thattai M, Kurtser I, Grossman AD, van Oudenaarden A. Regulation of noise in the expression of a single gene. Nat Genet. 2002;31: 69-73. https://doi.org/10.1038/ng869.

32. Palomero T, et al. NOTCH1 directly regulates c-MYC and activates a feedforward-loop transcriptional network promoting leukemic cell growth. Proc Natl Acad Sci U S A. 2006;103:18261-6. https://doi.org/10.1073/pnas. 0606108103.

33. Weng AP, et al. c-Myc is an important direct target of Notch1 in T-cell acute lymphoblastic leukemia/lymphoma. Genes Dev. 2006;20:2096-109. https:// doi.org/10.1101/gad.1450406.

34. Zeller Kl, et al. Global mapping of c-Myc binding sites and target gene networks in human B cells. Proc Natl Acad Sci U S A. 2006;103:17834-9. https://doi.org/10.1073/pnas.0604129103.

35. van Riggelen J, Yetil A, Felsher DW. MYC as a regulator of ribosome biogenesis and protein synthesis. Nat Rev Cancer. 2010;10:301-9. https://doi. org/10.1038/nrc2819.

36. Grandori C, et al. c-Myc binds to human ribosomal DNA and stimulates transcription of rRNA genes by RNA polymerase I. Nat Cell Biol. 2005;7:3118. https://doi.org/10.1038/ncb1224.

37. Boon $\mathrm{K}$, et al. $\mathrm{N}$-myc enhances the expression of a large set of genes functioning in ribosome biogenesis and protein synthesis. EMBO J. 2001;20: 1383-93. https://doi.org/10.1093/emboj/20.6.1383.

38. Schmidt EV. The role of c-myc in regulation of translation initiation. Oncogene. 2004;23:3217-21. https://doi.org/10.1038/sj.onc.1207548.

39. Chan SM, Weng AP, Tibshirani R, Aster JC, Utz PJ. Notch signals positively regulate activity of the mTOR pathway in T-cell acute lymphoblastic leukemia. Blood. 2007;110:278-86. https://doi.org/10.1182/blood-2006-08039883.

40. Kim J, Kundu M, Viollet B, Guan KL. AMPK and mTOR regulate autophagy through direct phosphorylation of Ulk1. Nat Cell Biol. 2011:13:132-U171. https://doi.org/10.1038/ncb2152.

41. Mayer C, Grummt I. Ribosome biogenesis and cell growth: mTOR coordinates transcription by all three classes of nuclear RNA polymerases. Oncogene. 2006;25:6384-91. https://doi.org/10.1038/sj.onc.1209883.

42. Warner JR. The economics of ribosome biosynthesis in yeast. Trends Biochem Sci. 1999;24:437-40.

43. Warner JR, Vilardell J, Sohn JH. Economics of ribosome biosynthesis. Cold Spring Harb Symp Quant Biol. 2001;66:567-74.

44. Kierzek AM, Zaim J, Zielenkiewicz P. The effect of transcription and translation initiation frequencies on the stochastic fluctuations in prokaryotic gene expression. J Biol Chem. 2001;276:8165-72. https://doi.org/ 10.1074/jbc.M006264200.
45. McAdams HH, Arkin A. Stochastic mechanisms in gene expression. Proc Nat Acad Sci U S A. 1997;94:814-9. https://doi.org/10.1073/pnas.94.3.814.

46. Liang J, Slingerland JM. Multiple roles of the PI3K/PKB (Akt) pathway in cell cycle progression. Cell Cycle. 2003;2:339-45.

47. Shtutman M, et al. The cyclin D1 gene is a target of the beta-catenin/LEF-1 pathway. Proc Natl Acad Sci U S A. 1999;96:5522-7. https://doi.org/10.1073/ pnas.96.10.5522

48. Maccario $H$, Pereira NM, Davidson L, Downes CP, Leslie NR. PTEN is destabilized by phosphorylation on Thr(366). Biochem J. 2007;405:439-44. https://doi.org/10.1042/Bj20061837.

49. Carracedo A, Pandolfi PP. The PTEN-PI3K pathway: of feedbacks and crosstalks. Oncogene. 2008;27:5527-41. https://doi.org/10.1038/onc.2008.247.

50. Hermida MA, Dinesh Kumar J, Leslie NR. GSK3 and its interactions with the PI3KJAKT/mTOR signalling network. Adv Biol Regul. 2017;65:5-15. https:// doi.org/10.1016/j.jbior.2017.06.003.

51. Wong GW, Knowles GC, Mak TW, Ferrando AA, Zuniga-Pflucker JC. HES1 opposes a PTEN-dependent check on survival, differentiation, and proliferation of TCRbeta-selected mouse thymocytes. Blood. 2012;120:143948. https://doi.org/10.1182/blood-2011-12-395319.

52. Kaur M, Cole MD. MYC acts via the PTEN tumor suppressor to elicit autoregulation and genome-wide gene repression by activation of the Ezh2 methyltransferase. Cancer Res. 2013;73:695-705. https://doi.org/10.1158/ 0008-5472.CAN-12-2522

53. Alon U. Network motifs: theory and experimental approaches. Nat Rev Genet. 2007;8:450-61. https://doi.org/10.1038/nrg2102.

54. Rossig $L$, et al. Akt-dependent phosphorylation of p21(Cip1) regulates PCNA binding and proliferation of endothelial cells. Mol Cell Biol. 2001;21:5644-57. https://doi.org/10.1128/MCB.21.16.5644-5657.2001.

55. Serra $\mathrm{H}$, et al. PTEN mediates Notch-dependent stalk cell arrest in angiogenesis. Nat Commun. 2015;6:7935. https://doi.org/10.1038/ ncomms8935.

56. Behrens J, et al. Functional interaction of beta-catenin with the transcription factor LEF-1. Nature. 1996;382:638-42. https://doi.org/10.1038/382638a0.

57. Wu Cl, et al. Function of Wnt/beta-catenin in counteracting Tcf3 repression through the Tcf3-beta-catenin interaction. Development. 2012;139:2118-29. https://doi.org/10.1242/dev.076067.

58. He TC, et al. Identification of c-MYC as a target of the APC pathway. Science. 1998;281:1509-12. https://doi.org/10.1126/science.281.5382.1509.

59. Riascos-Bernal DF, et al. beta-Catenin C-terminal signals suppress p53 and are essential for artery formation. Nat Commun. 2016;7:12389. https://doi. org/10.1038/ncomms12389.

60. Levine AJ. p53, the cellular gatekeeper for growth and division. Cell. 1997; 88:323-31.

61. Rother $\mathrm{K}$, et al. p53 downregulates expression of the G1/S cell cycle phosphatase Cdc25A. Oncogene. 2007;26:1949-53. https://doi.org/10.1038/ sj.onc.1209989.

62. Farahani $\mathrm{R}$, Rezaei-Lotfi S, Simonian M, Hunter N. Bi-modal reprogramming of cell cycle by MiRNA-4673 amplifies human neurogenic capacity. Cell Cycle. 2019;18:848-68. https://doi.org/10.1080/15384101.2019.1595873.

63. Hayward P, Kalmar T, Arias AM. Wnt/Notch signalling and information processing during development. Development. 2008;135:411-24. https://doi. org/10.1242/dev.000505

64. Kwon C, et al. Notch post-translationally regulates beta-catenin protein in stem and progenitor cells. Nat Cell Biol. 2011;13:1244-51. https://doi.org/10. 1038/ncb2313.

65. Kim TK, et al. Widespread transcription at neuronal activity-regulated enhancers. Nature. 2010;465:182-7. https://doi.org/10.1038/nature09033.

66. Fang $\mathrm{D}$, et al. Phosphorylation of beta-catenin by AKT promotes betacatenin transcriptional activity. J Biol Chem. 2007;282:11221-9. https://doi. org/10.1074/jbc.M611871200.

67. Menard M, et al. Hey1- and p53-dependent TrkC proapoptotic activity controls neuroblastoma growth. PLoS Biol. 2018;16:e2002912. https://doi. org/10.1371/journal.pbio.2002912.

68. Duursma A, Agami R. p53-dependent regulation of Cdc6 protein stability controls cellular proliferation. Mol Cell Biol. 2005;25:6937-47. https://doi.org/ 10.1128/MCB.25.16.6937-6947.2005.

69. Pelizon C. Down to the origin: Cdc6 protein and the competence to replicate. Trends Cell Biol. 2003;13:110-3.

70. Prasanth SG, Mendez J, Prasanth KV, Stillman B. Dynamics of pre-replication complex proteins during the cell division cycle. Philos Trans R Soc Lond Ser B Biol Sci. 2004;359:7-16. https://doi.org/10.1098/rstb.2003.1360. 
71. Noseda M, Niessen K, McLean G, Chang L, Karsan A. Notch-dependent cell cycle arrest is associated with downregulation of minichromosome maintenance proteins. Circ Res. 2005;97:102-4. https://doi.org/10.1161/01. Res.0000174380.06673.81.

72. Nakagawa O, et al. Members of the HRT family of basic helix-loop-helix proteins act as transcriptional repressors downstream of Notch signaling. Proc Natl Acad Sci U S A. 2000;97:13655-60. https://doi.org/10.1073/pnas. 250485597.

73. Murata K, et al. Hes1 directly controls cell proliferation through the transcriptional repression of p27(Kip1). Mol Cell Biol. 2005;25:4262-71. https://doi.org/10.1128/Mcb.25.10.4262-4271.2005.

74. Monahan P, Rybak S, Raetzman LT. The notch target gene HES1 regulates cell cycle inhibitor expression in the developing pituitary. Endocrinology. 2009;150:4386-94. https://doi.org/10.1210/en.2009-0206.

75. Georgia S, Soliz R, Li M, Zhang P, Bhushan A. p57 and Hes1 coordinate cell cycle exit with self-renewal of pancreatic progenitors. Dev Biol. 2006;298:2231. https://doi.org/10.1016/j.ydbio.2006.05.036.

76. Zalc A, et al. Antagonistic regulation of p57kip2 by Hes/hey downstream of notch signaling and muscle regulatory factors regulates skeletal muscle growth arrest. Development. 2014;141:2780-90. https://doi.org/10.1242/dev. 110155.

77. Wu X, et al. Autophagy regulates Notch degradation and modulates stem cell development and neurogenesis. Nat Commun. 2016;7:10533. https:// doi.org/10.1038/ncomms10533

78. Karbowniczek M, et al. The evolutionarily conserved TSC/Rheb pathway activates notch in tuberous sclerosis complex and Drosophila external sensory organ development. J Clin Invest. 2010;120:93-102. https://doi.org/ $10.1172 / \mathrm{JCl} 40221$

79. Jung $\mathrm{CH}$, Ro SH, Cao J, Otto NM, Kim DH. mTOR regulation of autophagy. FEBS Lett. 2010;584:1287-95. https://doi.org/10.1016/j.febslet. 2010.01.017

80. Mizushima N. The role of the Atg1/ULK1 complex in autophagy regulation. Curr Opin Cell Biol. 2010;22:132-9. https://doi.org/10.1016/j. ceb.2009.12.004

81. Zhou J, et al. Activation of the PTEN/mTOR/STAT3 pathway in breast cancer stem-like cells is required for viability and maintenance. Proc Natl Acad Sci U S A. 2007;104:16158-63. https://doi.org/10.1073/pnas.0702596104.

82. Inoki K, Li Y, Zhu TQ, Wu J, Guan KL. TSC2 is phosphorylated and inhibited by Akt and suppresses mTOR signalling. Nat Cell Biol. 2002;4:648-57. https:// doi.org/10.1038/ncb839.

83. Marcel N, Sarin A. Notch1 regulated autophagy controls survival and suppressor activity of activated murine T-regulatory cells. Elife. 2016;5. https://doi.org/10.7554/eLife.14023.

84. Levine B, Abrams J. p53: the Janus of autophagy? Nat Cell Biol. 2008;10:6379. https://doi.org/10.1038/ncb0608-637.

85. Mizushima N, Levine B. Autophagy in mammalian development and differentiation. Nat Cell Biol. 2010;12:823-30. https://doi.org/10.1038/ ncb0910-823.

86. Stitzel ML, Seydoux G. Regulation of the oocyte-to-zygote transition. Science. 2007;316:407-8. https://doi.org/10.1126/science.1138236.

87. Wu Y, et al. Autophagy and mTORC1 regulate the stochastic phase of somatic cell reprogramming. Nat Cell Biol. 2015;17:715-25. https://doi.org/ 10.1038/ncb3172.

88. Ronchini C, Capobianco AJ. Induction of cyclin D1 transcription and CDK2 activity by Notch(ic): implication for cell cycle disruption in transformation by Notch(ic). Mol Cell Biol. 2001;21:5925-34. https://doi.org/10.1128/mcb.21. 17.5925-5934.2001.

89. Campa VM, et al. Notch activates cell cycle reentry and progression in quiescent cardiomyocytes. J Cell Biol. 2008;183:129-41. https://doi.org/10. 1083/jcb.200806104

90. Bellot $\mathrm{G}$, et al. Hypoxia-induced autophagy is mediated through hypoxiainducible factor induction of BNIP3 and BNIP3L via their BH3 domains. Mo Cell Biol. 2009;29:2570-81. https://doi.org/10.1128/Mcb.00166-09.

91. Russell RC, Yuan HX, Guan KL. Autophagy regulation by nutrient signaling. Cell Res. 2014;24:42-57. https://doi.org/10.1038/cr.2013.166

92. Eiraku $M$, et al. Self-organizing optic-cup morphogenesis in threedimensional culture. Nature. 2011;472:51-6. https://doi.org/10.1038/ nature09941.

93. Toda S, Blauch LR, Tang SKY, Morsut L, Lim WA. Programming selforganizing multicellular structures with synthetic cell-cell signaling. Science. 2018;361:156-62. https://doi.org/10.1126/science.aat0271.
94. Maurer U, Preiss F, Brauns-Schubert P, Schlicher L, Charvet C. GSK-3 - at the crossroads of cell death and survival. J Cell Sci. 2014;127:1369-78. https:// doi.org/10.1242/jcs.138057.

95. Kastan MB, Onyekwere O, Sidransky D, Vogelstein B, Craig RW. Participation of p53 protein in the cellular response to DNA damage. Cancer Res. 1991; 51:6304-11.

96. Mercurio F, Manning AM. NF-kappaB as a primary regulator of the stress response. Oncogene. 1999;18:6163-71. https://doi.org/10.1038/sj.onc. 1203174.

97. Khaled M, et al. Glycogen synthase kinase 3beta is activated by CAMP and plays an active role in the regulation of melanogenesis. J Biol Chem. 2002; 277:33690-7. https://doi.org/10.1074/jbc.M202939200.

98. Roh MS, et al. Hypoxia activates glycogen synthase kinase-3 in mouse brain in vivo: protection by mood stabilizers and imipramine. Biol Psychiatry. 2005:57:278-86. https://doi.org/10.1016/j.biopsych.2004.10.039.

99. Foltz DR, Santiago MC, Berechid BE, Nye JS. Glycogen synthase kinase-3beta modulates notch signaling and stability. Curr Biol. 2002;12:1006-11.

100. Lefort K, et al. Notch1 is a p53 target gene involved in human keratinocyte tumor suppression through negative regulation of ROCK1/2 and MRCKalpha kinases. Genes Dev. 2007;21:562-77. https://doi.org/10.1101/gad.1484707.

101. Bash J, et al. Rel/NF-kappaB can trigger the Notch signaling pathway by inducing the expression of Jagged1, a ligand for Notch receptors. EMBO J. 1999;18:2803-11. https://doi.org/10.1093/emboj/18.10.2803.

102. Moran ST, et al. Synergism between NF-kappa B1/p50 and Notch2 during the development of marginal zone B lymphocytes. J Immunol. 2007;179: 195-200.

103. Shin HM, et al. Notch1 augments NF-kappaB activity by facilitating its nuclear retention. EMBO J. 2006;25:129-38. https://doi.org/10.1038/sj.emboj. 7600902.

104. Saravanamuthu SS, Gao CY, Zelenka PS. Notch signaling is required for lateral induction of Jagged1 during FGF-induced lens fiber differentiation. Dev Biol. 2009:332:166-76. https://doi.org/10.1016/j.ydbio.2009.05.566.

105. Hartman BH, Reh TA, Bermingham-McDonogh O. Notch signaling specifies prosensory domains via lateral induction in the developing mammalian inner ear. Proc Natl Acad Sci U S A. 2010;107:15792-7. https://doi.org/10. 1073/pnas.1002827107.

106. Lai Q, Zhao XW, Huang JN, Pham VT, Rajagopal K. Monostability, bistability, periodicity and chaos in gene regulatory network. Eur Phys J-Spec Top. 2018;227:719-30. https://doi.org/10.1140/epjst/e2018-700132-8.

107. Pomerening JR. Uncovering mechanisms of bistability in biological systems. Curr Opin Biotechnol. 2008;19:381-8. https://doi.org/10.1016/j.copbio.2008. 06.009 .

108. Khajuria RK, et al. Ribosome levels selectively regulate translation and lineage commitment in human hematopoiesis. Cell. 2018;173:90-103 e119. https://doi.org/10.1016/j.cell.2018.02.036.

109. Sanchez CG, et al. Regulation of ribosome biogenesis and protein synthesis controls Germline stem cell differentiation. Cell Stem Cell. 2016:18:276-90. https://doi.org/10.1016/j.stem.2015.11.004

110. Hsieh JJD, et al. Truncated mammalian Notch1 activates CBF1/RBP Jkrepressed genes by a mechanism resembling that of Epstein-Barr virus EBNA2. Mol Cell Biol. 1996:16:952-9.

111. Ross DA, Kadesch T. The notch intracellular domain can function as a coactivator for LEF-1. Mol Cell Biol. 2001;21:7537-44. https://doi.org/10.1128/ Mcb.21.22.7537-7544.2001.

112. Ewaskow SP, et al. Mutation and modeling analysis of the Saccharomyces cerevisiae Swi6 ankyrin repeats. Biochemistry. 1998;37:4437-50. https://doi. org/10.1021/bi972652e.

113. Sidorova J, Breeden L. Analysis of the SWI4/SWI6 protein complex, which directs G1/S-specific transcription in Saccharomyces cerevisiae. Mol Cell Biol. 1993;13:1069-77. https://doi.org/10.1128/mcb.13.2.1069.

114. Mizushima N. Autophagy: process and function. Genes Dev. 2007:21:286173. https://doi.org/10.1101/gad.1599207.

115. Mathiassen SG, De Zio D, Cecconi F. Autophagy and the cell cycle: a complex landscape. Front Oncol. 2017;7:51. https://doi.org/10.3389/fonc. 2017.00051.

116. Shaw J, Payer K, Son S, Grover WH, Manalis SR. A microfluidic "baby machine" for cell synchronization. Lab Chip. 2012;12:2656-63. https://doi. org/10.1039/c2lc40277g.

117. Arias AM, Hayward P. Filtering transcriptional noise during development: concepts and mechanisms. Nat Rev Genet. 2006;7:34-44. https://doi.org/10. 1038/nrg1750 
118. Rezaei-Lotfi S, Hunter N, M Farahani R. $\beta$-catenin: a metazoan filter for biological noise? Front. Genet. 2019. https://doi.org/10.3389/fgene.2019. 01004.

119. Rezaei-Lotfi S, Hunter N, Farahani RM. Coupled cycling programs

multicellular self-organization of neural progenitors. Cell Cycle. 2019;18: 2040-54. https://doi.org/10.1080/15384101.2019.1638692.

\section{Publisher's Note}

Springer Nature remains neutral with regard to jurisdictional claims in published maps and institutional affiliations.

Ready to submit your research? Choose BMC and benefit from:

- fast, convenient online submission

- thorough peer review by experienced researchers in your field

- rapid publication on acceptance

- support for research data, including large and complex data types

- gold Open Access which fosters wider collaboration and increased citations

- maximum visibility for your research: over $100 \mathrm{M}$ website views per year

At BMC, research is always in progress.

Learn more biomedcentral.com/submissions 